for patients using either inhaler, although achieving inhaler mastery was significantly greater in patients using Spiromax compared with Turbohaler at baseline. A higher, non-significant percentage of patients using Spiromax maintained inhaler mastery (assessed by HCPs). This result was supported by significantly higher odds of maintaining mastery when HCP errors were calibrated using independent video assessment in patients using Spiromax (consented videos available for 243/305 patients [79\%]). Maintaining inhaler mastery improved asthma control in both treatment groups and was not significantly different (Table 1).

Conclusions The proportion of patients achieving inhaler mastery at baseline was significantly greater for Spiromax compared with Turbohaler; no significant difference was found in inhaler mastery at 12 weeks. Patients using Spiromax made significantly fewer errors overall (HCP-observed and HCP- and technologyobserved) than patients using Turbohaler. Maintaining inhaler mastery improved asthma control in both treatment groups. Independent video assessment can assist HCPs in evaluating device mastery, and is proposed as the gold standard in such studies.

\section{P155 FLUTICASONE FUROATE (FF)/VILANTEROL (VI) ONCE DAILY REDUCES RESCUE MEDICATION USE BOTH DAY AND NIGHT}

${ }^{1}$ LA Jacques, ${ }^{2} R$ Forth, ${ }^{3} \mathrm{~L}$ Yates, ${ }^{1} \mathrm{DA}$ Leather. ${ }^{1}$ Respiratory Medicines Development Centre, GlaxoSmithKline, London, UK; ${ }^{2}$ PAREXEL International Research Triangle Park, Durham, USA; ${ }^{3}$ GlaxoSmithKline Respiratory Global Franchise, London, UK
Introduction and objectives FF/VI is the first once daily inhaled corticosteroid/long-acting $b_{2}$-agonist combination available for the treatment of asthma. Data from five phase III studies that have previously been presented have generally demonstrated a sustained $24 \mathrm{~h}$ improvement in lung function and improvement in rescue-free $24 \mathrm{~h}$ periods compared with placebo (P), FF alone or fluticasone propionate (FP). Due to differences in study comparators, duration of study and primary endpoints, integration of the study results has not been possible therefore each study is considered separately.

Methods Post-hoc analyses of diary card data from the 5 studies were performed to examine whether there was any difference in the contribution of the day and night time rescue medication use to the $24 \mathrm{~h}$ rescue-free period. Patients recorded in an electronic diary card the number of inhalations of rescue salbutamol/albuterol inhalation aerosol used during the day and night.

To be counted as rescue-free during the day or night the patient needed to record a no use of rescue medication during that period.

Results The post-hoc analyses demonstrated that the improvements in day and night time rescue -free periods were similar to the $24 \mathrm{~h}$ rescue free periods. See Figure 1 below.

Conclusions In general the benefit of FF/VI on rescue free $24 \mathrm{~h}$ periods is reflected in the improvements seen in day and night time rescue use.

10.1136/thoraxjn-2015-207770.292

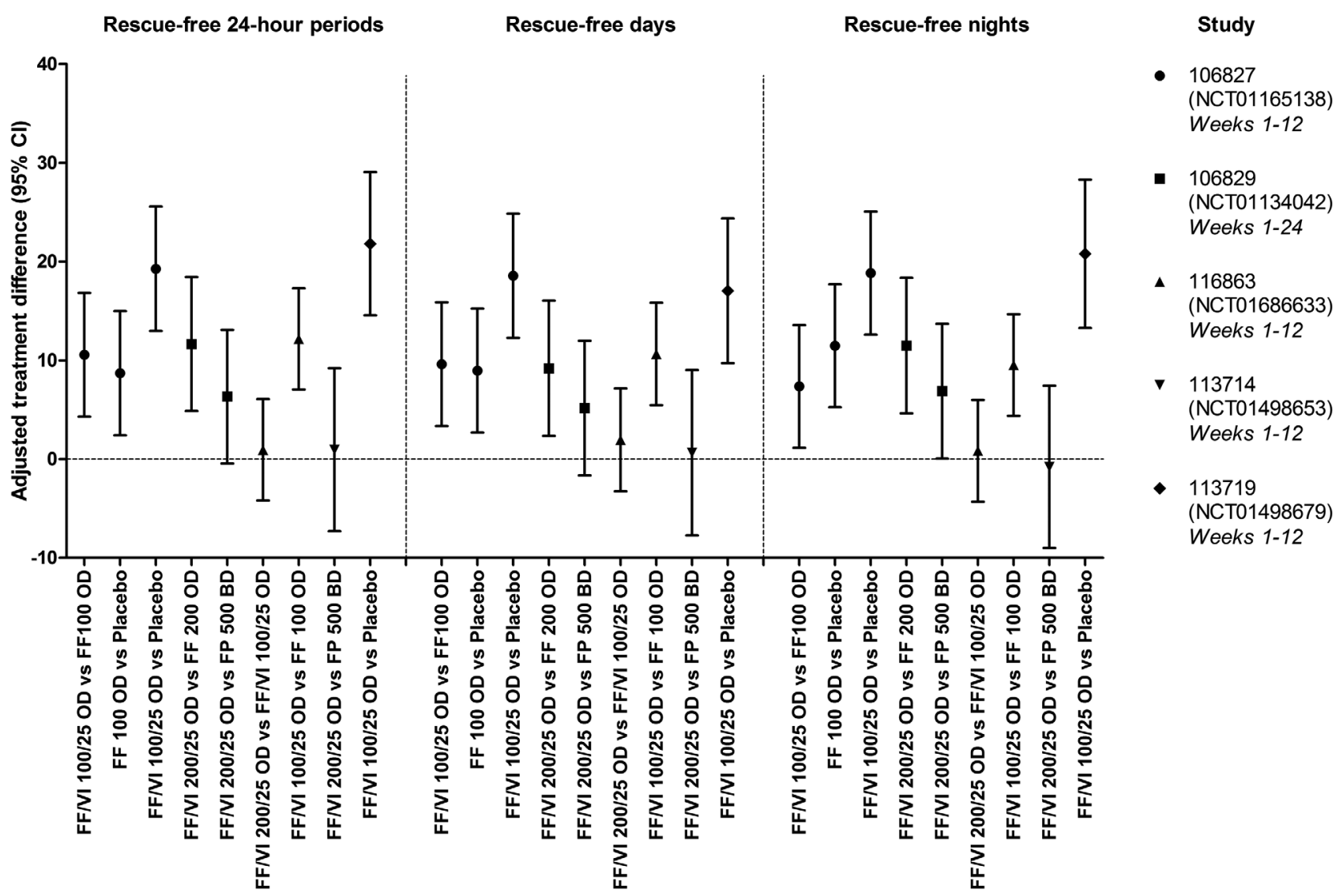

Abstract P155 Figure 1 